\title{
SENAI: Resultados e Visão de Futuro
}

Desde a sua fundação, há 70 anos, o Serviço Nacional de Aprendizagem Industrial (SENAI) vem cumprindo sua missão de elevar a competitividade da indústria brasileira por meio da educação profissional e tecnológica, da inovação e da transferência de tecnologia. Como resultado, 55 milhões de brasileiros foram capacitados, transformando a entidade numa das maiores redes de educação profissional do mundo. Atuando em todas as áreas industriais, possui uma capacidade de oferecer mais de 2 milhões de matrículas anuais, além de prestar serviços tecnológicos a mais de 80 mil empresas por ano. Por meio da prestação de serviços técnicos e tecnológicos, como consultoria em processo produtivo, serviços laboratoriais, desenvolvimento de produtos e informação tecnológica, o SENAI busca prover soluções de qualidade para gargalos tecnológicos da indústria brasileira.

No campo da inovação, o Programa SENAI de Inovação busca integrar a rede de serviços tecnológicos dos centros da entidade às demandas da indústria. Essa ação conjunta vem permitindo uma nova abordagem da produção e difusão do conhecimento para a competitividade nacional. Dentro do Programa, o SENAI/ DN criou instrumentos para operacionalizar ações de inovação, tais como o Edital SENAI Inovação, que desde 2004 atendeu mais de 340 empresas no desenvolvimento de soluções inovadoras, que permitiram a ampliação da capacidade produtiva, aumento de flexibilidade de produção e/ou redução dos custos de produção, redução de impactos ambientais, de segurança ou no consumo de energia e adequação do produto e/ou processo às regulamentações do país ou de mercado externo.

Agora, prepara-se para um novo desafio. De acordo com no Relatório Global de Competitividade 2010, do Fórum Econômico Mundial, o Brasil foi classificado como um país de economia de eficiência, ainda sem alcançar a competitividade direcionada para a inovação. Além disso, o Instituto de Estudos para o Desenvolvimento Industrial divulgou o grau de dependência tecnológica da indústria brasileira, avaliando que a balança comercial brasileira dos bens típicos da indústria de transformação, apresentou expressivo déficit de US\$ 35,3 bilhões no acumulado dos três trimestres inicias de 2011, demonstrando uma elevada demanda por serviços tecnológicos de alto valor agregado pelas indústrias brasileiras.

Frente a esses desafios de competitividade, o governo brasileiro lançou o Programa Brasil Maior (PBM), estabelecendo a nova política industrial, tecnológica, de serviços e de comércio exterior - cujo foco é a inovação tecnológica e o adensamento produtivo, visando intensificar a progressão tecnológica da indústria de transformação e impulsionar a qualificação profissional de nível técnico e superior, particularmente das engenharias. Dentro do programa, o Ministério da Ciência, Tecnologia e Inovação (MCTI), apóia o PBM por meio de três programas federais voltados para a formação profissional e inovação, dois deles com participação expressiva do SENAI: o Programa Nacional de Acesso ao Ensino Técnico e Emprego (PRONATEC), e o Programa Ciência Sem Fronteiras (PCsF).

Em sinergia com o governo e as indústrias, a Confederação Nacional da Indústria (CNI), através da Mobilização Empresarial pela Inovação (MEI) assumiu a inovação como o tema mais importante a ser estimulado na prática empresarial do setor industrial. A agenda de inovação da MEI, levada pela CNI a diversas instâncias políticas, contempla dez tópicos de interesse do setor:

1) Atração de centros de $P \& D$;

2) Internacionalizar as empresas, para ampliação da presença brasileira no exterior;

3) Disseminar a cultura da Propriedade Intelectual;

4) Formar recursos humanos, com ênfase em engenharia, ciências duras e ensino técnico; 
5) Aprimorar o marco legal da inovação;

6) Apoiar projetos estruturantes de P\&D em grande escala;

7) Definir instrumentos de apoio à projetos de $P \& D$ pré-competitivos;

8) Reduzir os diferenciais de produtividade entre grandes e pequenas empresas;

9) Articular inovação e comércio exterior

10) Atuar em Programas Setoriais de Inovação (políticas por setores e cadeias)

O financiamento à inovação é apontado como um gargalo estrutural, especialmente no desenvolvimento de P\&D pré-competitivo, estágio entre a prova do conceito inovador e a exploração em escala comercial do novo produto, processo ou serviço, envolvendo investimentos representativos em estudos de mercado, construção de protótipos, plantas piloto, engenharia de processo, avaliação de ensaios e teste. Uma forma de contornar este cenário seria focar a atuação no $\mathrm{P} \& \mathrm{D}$ pré-competitivo, a exemplo do Instituto Fraunhofer na Alemanha ou Kaist na Coréia do Sul, para viabilizar a aproximação da infraestrutura científica à realidade da demanda empresarial, nos aspectos de acesso a fomento e redução do tempo de operacionalização.

Perante esse cenário, a CNI, em conjunto com o SENAI Departamento Nacional, vem estruturando duas grandes ações de ampliação do papel do SENAI como agente do avanço da competitividade da indústria brasileira, reforçando a sua atuação estratégica em apoio aos programas e políticas estruturantes de interesse da indústria.
A primeira ação é desenvolver um projeto piloto com vistas à constituição da Empresa Brasileira de Pesquisa e Inovação Industrial (EMBRAPII), por meio do fomento a projetos de cooperação envolvendo empresas nacionais, Instituições Tecnológicas ou Instituições de direito privado sem fins lucrativos, voltadas para atividades de pesquisa e desenvolvimento, que objetivem a geração de produtos e processos inovadores. A segunda ação é o Programa SENAI de Apoio à Competitividade da Indústria Brasileira, que prevê a formação de mão-deobra para indústria e o aumento significativo da oferta de serviços técnicos e tecnológicos especializados em áreas estratégicas do conhecimento. Para elevar o patamar de atuação destes centros, serão implantados Institutos de Tecnologia com laboratórios de alto desempenho e Institutos de Inovação serão instalados, que desenvolverão pesquisa aplicada no estágio pré-competitivo.

Com essas ações, o SENAI estará cumprindo sua missão junto às empresas, ampliando a oferta de educação profissional e tecnológica de alta qualidade, serviços de alto desempenho e criando um ambiente favorável para o estabelecimento de uma economia baseada no conhecimento, tornando assim a indústria brasileira mais competitiva.

\section{Gustavo L. S. Filho}

Diretor de Operações do SENAI/DN.

e-mail: gfilho@dn.senai.br 